\title{
A New Long Proof of the Pythagorean Theorem
}

\author{
Salman Mahmud* \\ Student of BIAM Model School and College, Bogura, Bangladesh. \\ *Corresponding Author: Salman Mahmud, Student of BIAM Model School and College, Bogura, \\ Bangladesh.
}

\begin{abstract}
The Pythagorean theorem is the most famous theorem in the world. There seems to be about 500 different proofs of this theorem. Here in this article, I will show a new long proof of the theorem. Firstly, I will prove a formula which will help us to know the length of a square inscribed in a right triangle. The square will be inscribed in a right triangle so that one vertex of the square coincides with the right-angle vertex of the triangle. By using the formula to calculate the length of a inscribed square in a right triangle and by the help of similar triangles I will prove the Pythagorean theorem.
\end{abstract}

Keywords: Pythagorean theorem, new proof, Pythagoras, square inscribed in right triangle, similar triangles.

\section{INTRODUCTION}

There is an abundance of proofs available for Pythagoras' Theorem on right-angled triangles, from Pythagoras' own alleged proof in the $6^{\text {th }}$ century B.C., through Euclid's proof, the proof by Thabit ibn Qurra of Baghdad in the $9^{\text {th }}$ century, the Indian $12^{\text {th }}$ century mathematician Bhaskara's proof, to the one by the $20^{\text {th }}$ President of the United States James Garfield, who published his paper in 1876, five years before taking up office as President.

The aim of this paper is to present a new proof of the Pythagorean theorem. Firstly I will prove a formula which will help us to know the length of a square inscribed in a right triangle and the formula is $a b /(a+b)$, here $a$ and $b$ are the legs of a right triangle that's why we will be able to calculate the length of the square inscribed in a right triangle without using the length of hypotenuse. We know, in two similar triangles the ratios of the lengths of their corresponding sides are equal. In this prove some similar triangles will be used. By the help of similar triangles and the above formula the Pythagorean theorem will be easily proved.

\section{Pythagorean Theorem}

Ask anyone you happen to meet socially what theorem he/she remembers from high-school geometry. The chances are high that the reply would be the Pythagorean theorem. But if they are asked to state the theorem they may not be able to do so except, perhaps, to say that it concerns triangles and that the conclusion is $\mathrm{a}^{2}+\mathrm{b}^{2}=\mathrm{c}^{2}$.

It is believed that Pythagoras lived in the 6th century B. C. in the island of Samos, Egypt and in Croton in southern Italy, besides visits to neighbouring countries. He was the leader of a society, called Brotherhood, which was devoted to the study of mathematics, astronomy, religion and music. Among other things he is famous for the theorem attributed to him. The theorem was known earlier in some form or other in India and China; the Hindu mathematician Baudhayana discussed it around 800 B.C. in his book Baudhayana Sulba Sutra. It was known even earlier to the Babylonians.

Pythagoras seems to have been the one who formulated it in a form such that he is considered as the first pure mathematician in history. The theorem is called Pythagorean sometimes due to the secretive nature of his society. There is an interesting story of how he happened to notice the truth of the theorem. While waiting in a palace to be received by the king, his attention was drawn to the stone-square tiling of the floor. He imagined right angled triangles in half-squares implicit in the tiling together with the squares on its sides. It occurred to him that the area of the square over the hypotenuse of the right triangle is equal to the sum of the areas of the squares over the other two sides. Legend has it that Pythagorean brotherhood celebrated this discovery by sacrificing to gods a hetacomb (100 heads) of oxen! Regarding this, C. L. Dodgson (Lewis Carroll) wrote: "One can imagine oneself, even in these degenerate days, marking the epoch of some brilliant discovery by inviting a convivial friend or two, to 
join one in a beefsteak and a bottle of wine. But a hecatomb of oxen! It would produce a quite inconvenient supply of beef."

Is there a theorem in Euclidean geometry that has the most number of proofs?

Yes: the Pythagorean theorem. There seems to be about 500 different proofs of this theorem. The usual texts in geometry for high schools give the theorem in the form stated by Euclid, Book I, (Proposition 47): "In a right-angled triangle the square on the side subtending the right angle is equal to the squares on the sides containing the right angle" (Figure 1).

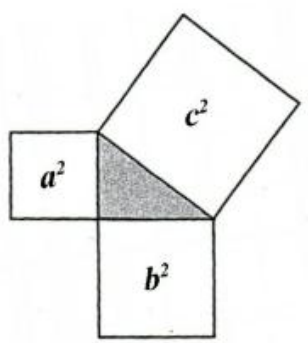

Figure1. A right-angled triangle with integer sides is called a Pythagorean triangle (PT).

Such a triangle with sides 3,4 and 5, with the hypotenuse of length 5, is the only PT with the three sides as consecutive numbers, and also the only triangle with the sum of the sides $(=12)$ which is double its area (=6). The next PT with consecutive leg lengths has sides 21, 20,29. The tenth such triangle has large sides: 27304196, 27304197, 38613965.

\section{The NeW Proof OF THE Pythagorean TheOREM}

The theorem that we are setting out to prove, the Pythagoras' Theorem, says the following. Take any right-angled triangle, in which the hypotenuse has a length of $\mathrm{c}$ and the other two sides lengths of a and b. The theorem asserts that $a^{2}+b^{2}=c^{2}$.

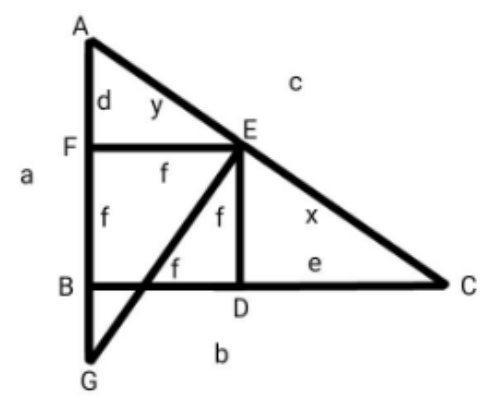

Figure2. Here $A B C$ is a right triangle and $B D E F$ is the inscribed square in the triangle. Here $D C>F B$ and $C D=F G$.

At first we have to increase $\mathrm{AB}$ to $\mathrm{G}$ so that $\mathrm{FG}$ becomes equal to $\mathrm{DC}$. Then we have to join $\mathrm{E}, \mathrm{G}$. According to drawing, here $\mathrm{DC}>\mathrm{FB}$ that's why we have to increase $\mathrm{AB}$. But when $\mathrm{DC}$ will be shorter than $\mathrm{FB}$ the point $\mathrm{G}$ will be on the line $\mathrm{AB}$ or $\mathrm{FB}$. That time the figure will be as following

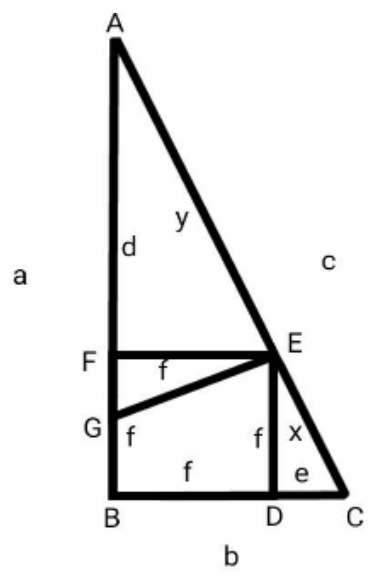

Figure2. Here $A B C$ is a right triangle and $B D E F$ is the inscribed square in the triangle. Here $D C<F B$ and $C D$ $=F G$. 
When DC and FB will be equal the figure will be as following,

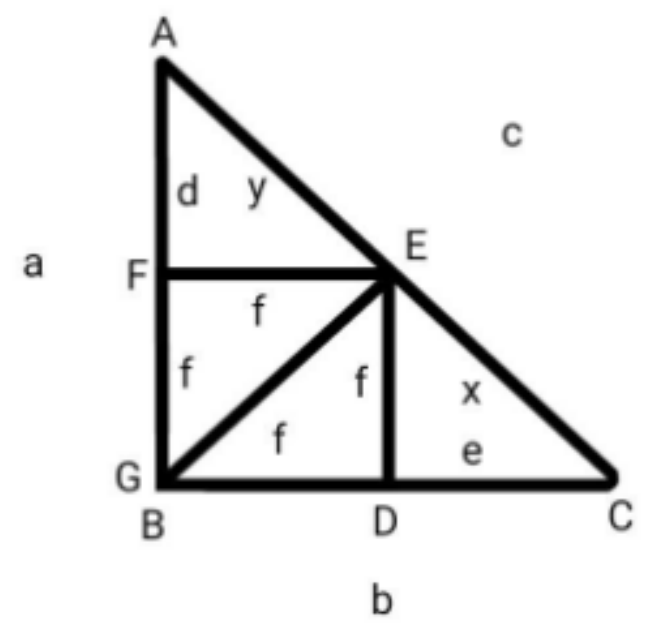

Figure 2": Here $\mathrm{ABC}$ is a right triangle and $\mathrm{BDEF}$ is the inscribed square in the triangle. Here $\mathrm{DC}=\mathrm{FB}$ and the point $G$ is on the point $B$. That's why sometimes we will consider the point $B$ as the point $G$ and sometimes will we consider it as point B. If we see the figure 2 and 2' we will know that DC is equal to $\mathrm{FG}$ and here $\mathrm{FB}=\mathrm{FG}$ that's why $\mathrm{B}$ and $\mathrm{G}$ are the same point.

Proof:

Here $A B=a, B C=b, A C=c, B D E F$ is a square that's why $B D=D E=E F=F B=f, a=d+f, b=e+$ $\mathrm{f}, \mathrm{c}=\mathrm{x}+\mathrm{y}, \mathrm{CD}=\mathrm{FG}=\mathrm{e}, \mathrm{AF}=\mathrm{d}$, (according to drawing), $\mathrm{EF} \| \mathrm{BC}$.

In the figures, $\mathrm{EF} \| \mathrm{BC}$

Therefore, $\angle \mathrm{AEF}=\angle \mathrm{ECD}$

In the case of triangle $\mathrm{AEF}$ and triangle $\mathrm{ECD}$

$\angle \mathrm{AFE}=\angle \mathrm{EDC}=90^{\circ}$

$\angle \mathrm{AEF}=\angle \mathrm{ECD}$

That's why $\triangle \mathrm{AEF} \sim \triangle \mathrm{ECD}$

So, $\frac{\mathrm{AF}}{\mathrm{DE}}=\frac{\mathrm{EF}}{\mathrm{CD}}$

$\Rightarrow \frac{\mathrm{d}}{\mathrm{f}}=\frac{\mathrm{f}}{\mathrm{e}}$

$\Rightarrow \frac{\mathrm{a}-\mathrm{f}}{\mathrm{f}}=\frac{\mathrm{f}}{\mathrm{b}-\mathrm{f}}$ [see figure- 2,2' and 2"]

$\Rightarrow \mathrm{f}^{2}=(\mathrm{a}-\mathrm{f})(\mathrm{b}-\mathrm{f})$

$\Rightarrow \mathrm{f}^{2}=\mathrm{ab}-\mathrm{af}-\mathrm{bf}+\mathrm{f}^{2}$

$\Rightarrow \mathrm{f}^{2-} \mathrm{f}^{2}+\mathrm{af}+\mathrm{bf}=\mathrm{ab}$

$\Rightarrow \mathrm{f}(\mathrm{a}+\mathrm{b})=\mathrm{ab}$

a $\quad \therefore \mathrm{f}=\frac{\mathrm{ab}}{\mathrm{a}+\mathrm{b}}$

Through this formula we can calculate the length of the square (like BDEF) inscribed in a right triangle. Again,

$\frac{\mathrm{AF}}{\mathrm{DE}}=\frac{\mathrm{AE}}{\mathrm{EC}}$

$\Rightarrow \frac{\mathrm{d}}{\mathrm{f}}=\frac{\mathrm{y}}{\mathrm{x}}$

$\therefore \mathrm{y}=\frac{\mathrm{dx}}{\mathrm{f}}$

Now,

$\mathrm{d}=\mathrm{a}-\frac{\mathrm{ab}}{\mathrm{a}+\mathrm{b}} \quad[\because \mathrm{d}=\mathrm{a}-\mathrm{f}]$

$=\frac{a^{2}+a b-a b}{a+b}$ 
$=\frac{a^{2}}{a+b}$

Again,

$e=b-\frac{a b}{a+b} \quad[\because e=b-f]$

$=\frac{a b+b^{2}-a b}{a+b}$

$=\frac{b^{2}}{a+b}$

Here,

$\mathrm{AG}=\mathrm{AF}+\mathrm{FG}$

$=\mathrm{AF}+\mathrm{CD} \quad[\because \mathrm{FG}=\mathrm{CD}]$

$=\mathrm{d}+\mathrm{e}$

$=\frac{a^{2}}{a+b}+\frac{b^{2}}{a+b}$

$=\frac{a^{2}+b^{2}}{a+b}$

Again,

$y=\frac{d x}{f} \quad$ [ see Eq. (1)]

$\Rightarrow y=\frac{\frac{a^{2}}{a+b} \times x}{\frac{a b}{a+b}}\left[\because d=\frac{a^{2}}{a+b}\right.$ and $\left.f=\frac{a b}{a+b}\right]$

$\Rightarrow y=\frac{x^{2}}{(a+b)} \times \frac{(a+b)}{a b}$

$\therefore \mathrm{y}=\frac{\mathrm{ax}}{\mathrm{b}}$

In the case of $\triangle \mathrm{FGE}$ and $\triangle \mathrm{ECD}$,

$\mathrm{EF}=\mathrm{DE}=\mathrm{f}$

$\mathrm{FG}=\mathrm{CD}=\mathrm{e}[$ According to drawing ]

And $\angle \mathrm{EFG}=\angle \mathrm{EDC}$

$\therefore \triangle \mathrm{FGE} \cong \triangle \mathrm{ECD}$

So, $\quad \angle \mathrm{FEG}=\angle \mathrm{DEC}$

And $\mathrm{EG}=\mathrm{EC}=\mathrm{x}$

Now, $\quad \angle \mathrm{AEF}+\angle \mathrm{DEC}=90^{\circ}$

Again, $\quad \angle \mathrm{FEG}=\angle \mathrm{DEC}$

That's why, $\angle \mathrm{AEF}+\angle \mathrm{FEG}=90^{\circ}$

$\therefore \angle \mathrm{AEG}=90^{\circ}[\because \angle \mathrm{AEF}+\angle \mathrm{FEG}=\angle \mathrm{AEG}]$

$\therefore \triangle \mathrm{AEG}$ is a right triangle.

Here, the area of the triangle AEG

$=\frac{1}{2} \times \mathrm{AE} \times \mathrm{EG}=\frac{1}{2} \times \mathrm{AG} \times \mathrm{EF}$

$\Rightarrow \frac{1}{2} \times \mathrm{y} \times \mathrm{x}=\frac{1}{2} \times \mathrm{AG} \times \mathrm{f}$

$\Rightarrow \frac{1}{2} \times \frac{a x}{b} \times x=\frac{1}{2} \times \frac{a^{2}+b^{2}}{a+b} \times \frac{a b}{a+b}$

$\Rightarrow \mathrm{x}^{2}=\frac{\left(\mathrm{a}^{2}+\mathrm{b}^{2}\right) \mathrm{ab} \times \mathrm{b}}{(\mathrm{a}+\mathrm{b})^{2} \times \mathrm{a}}$

$\therefore \mathrm{x}=\frac{\mathrm{b} \sqrt{\mathrm{a}^{2}+\mathrm{b}^{2}}}{\mathrm{a}+\mathrm{b}}$

By Combining Eq [2] and [3], we get,

$\mathrm{y}=\frac{\mathrm{a} \times \frac{\mathrm{b} \sqrt{\mathrm{a}^{2}+\mathrm{b}^{2}}}{\mathrm{a}+\mathrm{b}}}{\mathrm{b}}$

$=\frac{a b \sqrt{a^{2}+b^{2}}}{a+b} \times \frac{1}{b}$ 
$=\frac{a \sqrt{a^{2}+b^{2}}}{a+b}$

Now,

$x+y=\frac{b \sqrt{a^{2}+b^{2}}}{a+b}+\frac{a \sqrt{a^{2}+b^{2}}}{a+b}$

$\Rightarrow \quad c=\frac{b \sqrt{a^{2}+b^{2}}+a \sqrt{a^{2}+b^{2}}}{a+b}[\because c=x+y]$

$\Rightarrow \quad c=\frac{(a+b) \sqrt{a^{2}+b^{2}}}{(a+b)}$

$\Rightarrow \quad c=\sqrt{a^{2}+b^{2}}$

$\Rightarrow \quad c^{2}=a^{2}+b^{2}$

$\therefore \mathrm{a}^{2}+\mathrm{b}^{2}=\mathrm{c}^{2}$ [Proved]

4. Conclusion

From $6^{\text {th }}$ century B.C mathematicians are trying to prove the Pythagorean theorem differently. That's why there are so many proofs of this theorem. The Conclusions of this study are as follows:

- This study will help us to know more about right triangles. This study will also increase the number of proofs of Pythagorean theorem.

- We will be able to know more different uses of similar triangles in case of proving Pythagorean theorem.

\section{ACKNOWLEDGEMENTS}

I should thank MD. Shah Alam and MST. Sabina Yesmin for providing me with the help materials. I want to thank my friend Tanim for helping me.

\section{AUTHOR'S BIOGRAPHY}

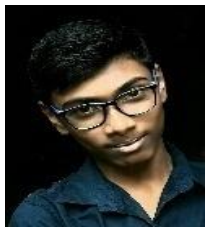

Salman Mahmud, is still a student of BIAM Model school and College, Bugura, Bangladesh. His core research interest is in modern physics. But he is interested in all the sectors of science. He wrote many research papers.

\section{REFERENCES}

[1] Swaminathan S (2014). The Pythagorean Theorem, Journal of Biodiversity, Bioprospecting and Development.vol.1, issue 3, doi : 10.4172/2376-0214.1000128

[2] B. Kaushik, 2015. "A New and Very Long Proof of the Pythagoras Theorem By Way of a Proposition on Isosceles Triangles," MPRA Paper 61125, University Library of Munich, Germany. https://ideas.repec.org/p/pra/mprapa/61125.html

[3] https://artofproblemsolving.com/wiki/index.php/2017_AMC_10A_Problems/Problem_21

[4] https://www.mathopenref.com/similartrianglesareas.h5.

[5] https://www.cut-the knot.org/pythagoras/

Citation: Salman Mahmud, Student of BIAM Model School and College, Bogura, Bangladesh., International Journal of Scientific and Innovative Mathematical Research (IJSIMR), vol. 7, no. 9, pp. 3-7, 2019. Available: DOI: http://dx.doi.org/10.20431/2347-3142.0709002

Copyright: () 2019 Authors. This is an open-access article distributed under the terms of the Creative Commons Attribution License, which permits unrestricted use, distribution, and reproduction in any medium, provided the original author and source are credited. 